\section{Antifertility Effects and Metabolism of $\alpha$ and epi-Chlorhydrins in the Rat}

THe ability of a variety of alkylating chemicals to produce infertility in male animals has long been established ${ }^{1}$ and investigations have shown that many such com. pounds are capable of alkylating genetic materials ${ }^{2}$. Their mutagenic effects in insects ${ }^{3}$ and the induction of dominant lethal mutations in experimental rodents ${ }^{4,5}$ are presumably the result of such interactions.

Recent observations that 3-chloropropane-1,2-diol ( $\alpha$ chlorhydrin) is capable of inducing sterility in male rats through interference with epididymal spermatozoa ${ }^{6,7}$ prompted our investigation of some aspects of its mode of action, particularly regarding the question of whether any alkylating mechanism could be involved. Because a mixture of $\alpha$-chlorhydrin with equimolar amounts of cysteine and sodium hydroxide at $37^{\circ} \mathrm{C}$ overnight produced 2,3-dihydroxypropyl-S-cysteine almost quantitatively, it was evident that alkylation readily occurred in vitro. Furthermore, Wistar rats dosed orally or intraperitoneally with $\alpha$-chlorhydrin $(50 \mathrm{mg} / \mathrm{kg}$ in aqueous solution) gave 2,3-dihydroxypropyl-S-cysteine and its $N$-acetate as urinary metabolites besides unchanged compound. We also found that epi-chlorhydrin (3-chloro1,2-epoxypropane) produced antifertility effects in rats resembling those due to $\alpha$-chlorhydrin at the same dose level. This could be explained by hydrolysis of the epoxide ring to give $\alpha$-chlorhydrin, supported by identification of the same urinary metabolites after epi-chlorhydrin as from $\alpha$-chlorhydrin. There is, however, also the possibility that $\alpha$-chlorhydrin might operate in the biological systom through an internal condensation to the epoxide, glycidol, 2,3-epoxy-1-propanol, a reaction not without precedent for similar compounds, for example, from 1,6-dibromomannitol ${ }^{8}$. This possibility is being investigated.

The appearance of substituted cysteine derivatives in urine from animals treated with $\alpha$-chlorhydrin is reflective of the general detoxication mechanism for compounds of the alkylating type, including alkyl halides ${ }^{9}$. The general distribution and incomplete metabolism recently reported for this compound ${ }^{10}$ imply adequate opportunity for reaction with many biological nucleophiles and the mechanism could therefore involve an alkylation process.

Alkylating sulphonic esters, producing sterility in rodents by affecting epididymal sperm, have been shown to induce dominant lethal mutations ${ }^{4,5}$, and a test of the possibility that $\alpha$-chlorhydrin may produce genetic damage of this type was made by oral administration of the compound to male rats at two dose levels (five daily doses of 10 and $5 \mathrm{mg} / \mathrm{kg}$ ). At no time within the first three weeks from the first dose was the number of dominant lethal mutations increased above the control value, although the transformation from sterility to normal fertility occurred between these two dose levels.

These findings raise interesting speculations. In $\alpha$ chlorhydrin we clearly have an active alkylating chemical possessing the specific biological property of "functionally" inactivating epididymal sperm and so producing temporary sterility without evidence so far of an associated mechanism involving genetic material. Alkylating chemicals have provided many compounds effectively interfering with various stages of the spermatogenic process of rodents resulting in phases of sterility ${ }^{1}$. There is evidence that pharmacological effects on normal proliferating cell systems can be dissociated by modifying the structure of alkylating chemicals. Do the present results mean that alkylation per se does not nccessarily carry a risk of genetic damage to progeny ? Alternatively, $\alpha$-chlorhydrin could be operating by some mechanism independently of its alkylating property, although it has been shown that the chlorine atom is an essential component for both antifertility ${ }^{11}$ and alkylating activity.

This work was supported by grants to the Unit of Reproductive Pharmacology from the Ford Foundation and the Wellcome Trust and to the Christie Hospital from the British Empire Cancer Campaign for Research.

A. R. JONES

P. DAvies

Unit of Reproductive Pharmacology,

The University,

Manchester M13 9PL.

K. Edwarus

H. JACKSON

Paterson Laboratories,

Christie Hospital and Holt Radium Institute,

Manchester M20 9BX.

Received July 18, 1969.

1 Jackson, H., Antifertility Compounds in the Male and Female, 214 (Thomas, Springfield, Illinois, 1966).

Brookes, P, and Lawley, P. D. Brit. Med, Bull. 20, 91 (1964).

3 Loveless, A., Genetic and Allied Effects of Alkylating Agents, 270 (Butterworth, London, 1966).

- Partington, M., and Jackson, H., Genet. Res., 4, 333 (1963).

${ }^{5}$ Partington, M., and Bateman, A. J., Heredity, 19, 191 (1964).

${ }^{6}$ Coppola, J. A., Life Sci., 8, 43 (1969).

7 Ericsson, R. J., and Baker, V. F., J. Reprod. Fert. (in the press).

8 Jarman, M., and Ross, W. C. J., Carbohyd. Res., 9, 139 (1969).

- Roberts, J. J., and Warwick, G. P., Biochem. Pharm., 1, 00 (1958).

9 Roberts, J. J., and Warwick, G. P., Biochem. Pharm., 1, 60 (1958).
10 Kirton, K. T., Ericsson, R. J. Miller, W. L.. Cornette, J. G., Forbes, A.D. Kirton, K. T., Ericsson, R. J., Miller, W. L., Corne

${ }^{11}$ Ericsson, R. J., and Youngdale, G. A., J. Reprod. Fert. (in the press).

\section{Mitochondrial Increase after Long-term Feeding of Morfamquat}

MorfamQUAT dichloride (MFQ) is a herbicide (Plant Protection Limited) which produces degeneration and necrosis of the proximal convoluted tubules in the kidney when administered to rats and dogs in acutely toxic doses. Ninety day feeding tests have, however, shown that low dietary conccntrations $(0.015$ per cent) cause marked enlargement of certain cells in a circumscribed area of the kidncy, remote from the proximal tubules and this preliminary report describes the histology, histochemistry and electron microscopy of these abnormal cells in rat kidneys.

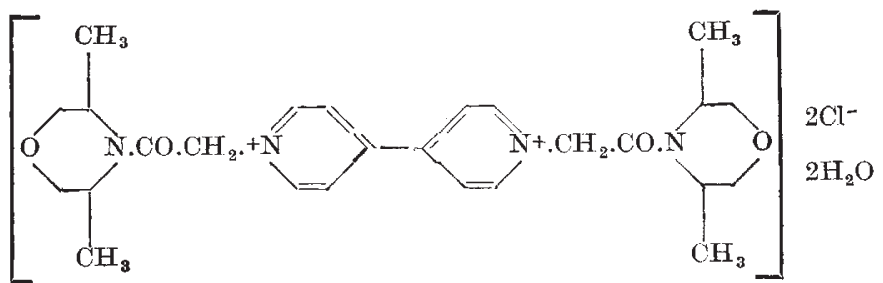

Adult male albino rats (Alderley Park strain) free from specific pathogens were fed a diet containing 0.015 per cent MFQ for 17 weeks and returned to a control diet free of MFQ for a further 4 weeks. Pairs of treated rats were killed at weekly intervals, beginning on the sixth week of feeding, and the kidneys were removed.

For light microscopy, 5 um paraffin sections were stained with haematoxylin and eosin. Enzyme histochemistry was performed on fresh frozen sections $6 \mu \mathrm{m}$ thick, and the following enzymes were examined before fixation: acid phosphatase ${ }^{1}$, leucine aminopeptidase ${ }^{2}$, nonspccific esterase $^{3}$, monoamine oxidase ${ }^{4}$, NAD and NADP diaphorases $^{5}$, cytochrome oxidase ${ }^{6}$, and six dehydrogenases: succinate, isocitrate, lactate, glucose-6-phosphate, $\alpha$ glycerolphosphate and $\beta$-hydroxybutyrate ${ }^{7,8}$. In tho electron microscope study, blocks were taken from the kidneys of one control and three test animals at 12, 13, 14 and 15 weeks. The blocks were fixed in 3 por cent 